\title{
A gramática do texto, no texto
}

\author{
Maria da Graça Costa Val \\ Universidade Federal de Minas Gerais
}

\section{Abstract}

This article focuses on grammatical teaching and it claims that a discursive approach of grammar in classroom is possible and useful to favor students' linguistic abilities development. At first, it presents an overview of theoretical discussion and practical proposes found in academic environments and in fundamental schools; finally it shows and discusses examples of exercises and activities which concerns both grammatical and textual-discursive knowledge of language. 
$\mathrm{N}$ uma palestra proferida no $\mathrm{CEALE}^{1} \mathrm{em} 29$ de março de 1994, o Professor Ataliba de Castilho, tratando das possibilidades língua falada dos alunos, justificou sua proposta declarando que já ultrapassamos a fase do diagnóstico e estamos, agora, no momento de formular terapêuticas para as dificuldades do ensino de Português. Dario Peito de Aço, mais conhecido como Dadá Maravilha, outro sábio, de outra área de atuação, sempre disse que para cada problemática é preciso encontrar a "solucionática". Aprendendo sempre com o Professor Ataliba e atleticana de coração, pretendo, neste artigo, apresentar minha contribuição para a construção coletiva e urgente dos saberes que possibilitarão ao professor de Língua Portuguesa ultrapassar as atuais perplexidades e realizar, com mais segurança, um trabalho útil ao desenvolvimento lingüístico dos alunos.

\section{DE QUE GRAMÁTICA ESTOU FALANDO?}

Nesta reflexão sobre o ensino de gramática não trago novidade absoluta, mas apresento minha "costura" de algumas idéias que circulam nas academias e nas escolas, no âmbito da discussão teórica e da prática que se vem realizando. O desenho desse panorama me encaminhará, ao final, a delinear uma proposta e a formular exemplos de atividades que ilustram algumas das possibilidades que entrevejo para uma prática de ensino de gramática compatível com uma visão discursiva da língua.

No terreno da teoria, vê-se, historicamente, a convivência conflituosa de diferentes concepções de língua e de gramática. Simplificando a discussão, que não é o objeto central deste trabalho, podem-se mencionar, com CASTILHO (1993), três maneiras de 
compreender a língua que se distribuem em três grandes "famílias teóricas" - a primeira, composta pelos estudos que vêem a língua como estrutura; a segunda, pelos que vêem a língua como atividade mental; a terceira, pelos que pensam a língua como atividade social.

São relativamente recentes as tentativas de integrar essas três vertentes, em razão de se considerar que cada uma delas contempla um dos subsistemas componentes de uma língua natural: o gramatical, o semântico-cognitivo e o discursivo. A concepção que orientou este trabalho alinha-se a essas tentativas integradoras, tomando como mutuamente constitutivas e interdependentes as dimensões gramatical, semântico-cognitiva e discursiva da língua, entendida como "sistematização" que se constitui na interlocução e para a interlocução, pela atividade lingüística coletiva dos falantes.

Da tradição de pensar a língua como arquitetura de formas (que hoje chamamos fonemas, morfemas, sintagmas, orações) e de buscar entender essa arquitetura, nos veio uma concepção de gramática como construto teórico que identifica unidades formais e descreve as relações entre essas unidades e suas possibilidades de combinação no interior do sistema. Correndo os riscos implicados pela generalização, pode-se dizer que essa concepção está na base de algumas tendências da tradição gramatical mais remota e dos modelos estruturalistas do século XX. Historicamente, o conceito tradicional de gramática, aliado a necessidades político-sociais de uniformização e valorização de uma língua nacional, resultou na legitimação de uma das variedades dessa língua como padrão culto e no estabelecimento de um conjunto de prescrições relativas ao emprego das formas em conformidade com as descrições da variedade de língua eleita como padrão. É o que nós conhecemos como gramática normativa.

Da teoria gerativa, que em sua fundação se apóia na concepção humboldtiana de língua como energeia, filiando-se à linhagem de estudos que vêem a língua como atividade mental, nos veio a noção de gramática como saber lingüístico do falante, internalizado de maneira ativa e produtiva desde os primeiros anos da infância. 
Na terceira família teórica, que prioriza a visão de língua como atividade social, podemos, como CASTILHO (1993), situar a Sociolingüistica, as teorias funcionalistas, os estudos da enunciação, do texto e do discurso. A Sociolingüística, apoiada de início nos princípios estruturalistas, estabeleceu a equivalência entre as diferentes variedades de uma língua, considerando cada uma um sistema, uma gramática completa e coerente. O funcionalismo, entendendo que as línguas têm a estrutura que têm porque funcionam como funcionam, propõe teorias gramaticais que lidam com conceitos voltados para o uso da língua, e não para as relações internas entre as formas do sistema. As teorias da enunciação, do texto e do discurso, de maneira ainda mais incisiva, têm deixado cada vez mais claro que não é possivel compreender verdadeiramente a natureza de uma língua isolando-a de seu funcionamento social e ignorando que esse sistema, historicamente, se organiza para servir à interação humana - fenômeno histórico, social, político e ideologicamente marcado. No quadro dessa última família teórica é que se pode pensar em gramática do texto/no texto, considerando-se, com o funcionalista DU BOIS (1993, apud NEVES, 1997, p. 29), que "a gramática é feita à imagem do discurso; mas o discurso nunca é observado sem a roupagem da gramática."

O que estou chamando de gramática do texto e no texto diz respeito ao conjunto de conhecimentos e habilidades dos falantes que lhes possibilita interagir lingüisticamente produzindo e interpretando textos, falados e escritos, nas diversas situações de sua vida; noutros termos, diz respeito ao saber internalizado dos falantes que os habilita a lidar com os recursos lingüísticos - gramaticais na produção e na compreensão dos textos que circulam nas práticas sociais de linguagem. É a gramática que "funciona" nesses textos.

Essa maneira de compreender e tratar a gramática se inspira em BAKHTIN (1986, p. 104-105) e no empenho desse estudioso no sentido de superar o "abismo intransponível" que se interpõe entre a sintaxe e o discurso nas abordagens formalistas da língua, dado que, para ele, a gramática da forma nada tem a contribuir para a compreensão dos processos discursivos. 


\section{ENSINO DE GRAMÁTICA: DIVERGÊNCIAS E CONVERGÊNCIAS}

Os avanços no campo teórico e a constatação empírica dos limites do modelo estabelecido de ensino de Português, centrado na descrição e na prescrição gramatical da variedade padrão, encaminharam a muitas discussões e múltiplas propostas, sobretudo nas duas últimas décadas. Num terreno marcado por divergências históricas quanto aos conceitos fundamentais, como se viu no item (1), e face a um problema complexo que tem raízes na mudança do perfil do alunado, as posições defendidas por lingüistas e educadores estão muito longe do consenso.

Entretanto, em meio ao confronto, uma tendência - ainda que não consensual - foi-se tornando mais visível e ganhando espaço, até chegar a configurar-se como fundamento teórico-metodológico assumido nos documentos oficiais de orientação do ensino no País, tais como propostas curriculares e critérios de avaliação de sistemas de ensino e de livros didáticos. Trata-se, em linhas gerais, da compreensão de que saber Português - saber a gramática do Português - significa ser capaz de interagir com sucesso nas diversas práticas sociais de linguagem, usando adequadamente diferentes variedades da língua, de acordo com as circunstâncias que condicionam esse uso.

Entre os primeiros marcos dessa vertente podem-se mencionar as reflexões de FRANCHI (1987) sobre criatividade e gramática e sua proposta de um trabalho em sala de aula voltado para o uso da língua e para a percepção das possibilidades de efeitos de sentido desencadeadas por diferentes arranjos dos recursos expressivos. Tiveram papel decisivo nessa história, inaugurando uma nova tradição, a "militância" e as publicações de GERALDI (1984, 1991, 1996, 1997), das quais destaco a proposta de que, na prática de ensino, a reflexão epilingüística tenha prioridade sobre a metalingüística. Merecem destaque, ainda, as discussões de POSSENTI (1984, 1988, 1996, 1998) sobre a dimensão política dos diferentes conceitos de gramática, bem como suas ponderações quanto às possíveis funções, no ensino, da gramática normativa, da gramática descritiva e da gramática internalizada do falante. Segundo esse autor, a escola 
deveria se empenhar em conhecer, respeitar e desenvolver a gramática internalizada dos alunos; ensinar-lhes elementos da gramática normativa necessários em determinadas situações de convívio numa sociedade não igualitária e discriminadora como a nossa; promover reflexões epilingüísticas, e metalingüísticas, que esclareçam e contribuam para o uso adequado da língua em diferentes circunstâncias. Outro estudioso que trouxe contribuição significativa para a compreensão do problema e a reorientação de seu equacionamento foi CASTILHO (1987, 1989, 1990, 1993 e 1998), com reflexões esclarecedoras sobre variação lingüística e com uma proposta articulada de um ensino que, como a história dos estudos lingüísticos no Ocidente, vá da retórica para a gramática, do discurso para a frase, da língua falada para a língua escrita, valendo-se, nessa trajetória, de início, das contribuições teóricas do funcionalismo, e só mais adiante, em estágios mais avançados, de modelos formais como o estruturalismo e o gerativismo.

Inspirados no mesmo quadro de princípios, os PCNs ( $5^{\mathrm{a}}$ a $8^{\mathrm{a}}$ séries) postulam que "o domínio da linguagem, como atividade discursiva e cognitiva, e o domínio da língua, como sistema utilizado por uma comunidade lingüística, são condições de possibilidade de plena participação social" (MINISTÉRIO DA EDUCAÇÃO, 1998, p. 19), e definem como objeto de ensino e de aprendizagem de Língua Portuguesa "o conhecimento lingüístico e discursivo com o qual o sujeito opera ao participar das práticas sociais mediadas pela linguagem" (p. 22). Especificamente quanto à reflexão sobre a linguagem, os PCNs de Língua Portuguesa (p. 78) advertem que "a criação de contextos efetivos de uso da linguagem é condição necessária, porém não suficiente, sobretudo no que se refere ao domínio pleno da modalidade escrita"; recomendam "a realização tanto de atividades epilingüísticas, que envolvem manifestações de um trabalho sobre a língua e suas propriedades, como de atividades metalingüísticas, que envolvam o trabalho de observação, descrição e categorização, por meio do qual se constroem explicações para os fenômenos lingüísticos das práticas discursivas"; mas alertam que "a prática de 
análise lingüística não é uma nova denominação para ensino de gramática”, nos moldes formalistas tradicionais. Em suma, propõem:

\begin{abstract}
"Tomando-se a linguagem como atividade discursiva, o texto como unidade de ensino e a noção de gramática como relativa ao conhecimento que o falante tem de sua linguagem, as atividades curriculares em Língua Portuguesa correspondem, principalmente, a atividades discursivas: uma prática constante de escuta de textos orais e leitura de textos escritos e de produção de textos orais e escritos, que devem permitir, por meio da análise e reflexão sobre os múltiplos aspectos envolvidos, a expansão e a construção de instrumentos que permitam ao aluno, progressivamente, ampliar sua competência discursiva." (p. 27)
\end{abstract}

Os PCNs (5 a $8^{a}$ ) foram publicados em 1998; antes disso já haviam sido divulgados os Parâmetros relativos às quatro primeiras séries do Ensino Fundamental, fundados sobre a mesma compreensão de língua e gramática; já contam mais de uma década propostas curriculares estaduais que apontam na mesma direção (São Paulo e Minas Gerais, entre outras). No entanto, persistem a perplexidade e o descontentamento dos professores. Por quê?

Porque, embora no âmbito das universidades e das instâncias de decisão das políticas públicas de ensino se possa até ter alcançado alguma clareza e alguma convergência quanto a alguns aspectos teóricos, essa discussão permanece restrita a círculos privilegiados de professores e educadores; grande número de profissionais do ensino só tem acesso à divulgação superficial de uma ou outra idéia, o que dificulta seu envolvimento efetivo no esforço de repensar a questão. A apropriação consistente de conceitos e princípios operatórios só virá como fruto do empenho coletivo de construir um saber prático, que possibilite ao professor alguma segurança quanto ao que fazer em sala de aula.

Entretanto, pode nos trazer certo conforto saber que esse não é um problema só brasileiro, explicável apenas pelos contra-sensos de nossa (des)organização social. Também nos países do chamado Primeiro Mundo ainda se fazem sentir os impactos da mudança de 
paradigma teórico provocada pelo fortalecimento e a expansão dos estudos da língua em uso, na enunciação e no discurso, nas práticas sociais "linguageiras".

Assim, por exemplo, um professor de didática de línguas da Universidade de Genebra, Jean-Paul Bronckart, tratando dessa questão em trabalho publicado em 1997 (tradução brasileira de 1999), considera que "modificar radicalmente o estatuto e o predomínio do ensino gramatical" constitui uma "impossibilidade social" contemporânea (BRONCKART, 1999, p. 87), em função das condições históricas de formação dos professores, de expectativas de pais, alunos e da comunidade em geral. $\mathrm{O}$ autor entende que o ideal seria um ensino que partisse do texto para a frase, articulando as reflexões relativas a um e outro nível, mas propõe apenas que a prática pedagógica se oriente pelo compromisso de evoluir na direção desse ideal, porque avalia como factível, hoje, nada mais que o desdobramento do ensino em "dois eixos paralelos" - o da gramática frasal e o do texto/discurso:

"De um lado, com base em um corpus de frases ou enunciados selecionados, a realização de atividades de inferência e codificação que levem a um domínio das principais noções e regras do sistema da língua (por exemplo, as regras de estruturação dos sintagmas, as características da conjugação do verbo, as regras de construção da frase passiva, etc.). De outro lado e simultaneamente, com base em um corpus de textos empíricos, também selecionados, a realização de atividades de sensibilização às condições de funcionamentos dos textos em seu contexto comunicativo, levando-se, localmente, à conceitualização de algumas regras de planejamento e textualização (por exemplo, as condições de emprego dos tempos verbais, dos organizadores textuais, das unidades anafóricas, etc.)." (p. 88)

Na tradição recente do ensino de Língua Portuguesa, o trabalho ou tem-se subdividido em três áreas estanques - leitura, produção de textos e gramática -, de modo que o que se discute com relação à compreensão dos textos lidos não se aplica ao trabalho com a produção de textos e esses dois componentes não têm eco nem respaldo na aula de gramática, ou tem-se sustentado na formação 
de dois blocos incomunicáveis - de um lado o estudo do texto, de outro o estudo da palavra e da frase.

Uma pesquisa realizada no CEALE no decorrer do ano 2000 revelou a presença dos "dois eixos paralelos" de que fala o professor suíço na organização de livros didáticos brasileiros inscritos no PNLD/2002. ${ }^{2}$ A maioria das coleções examinadas, retomando os três componentes tradicionais do ensino, não escapa à polarização entre o estudo do texto e o estudo da frase e da palavra. O que se observa, em geral, é análise morfológica e sintática de palavras, expressões e frases retiradas de um texto e focalizadas enquanto formas lingüísticas isoladas. O grande sinal de "modernidade", nesses casos, é que as formas analisadas são extraídas de histórias em quadrinhos, ou tirinhas, ou anedotas, por oposição a um estágio mais remoto do ensino em que se trabalhavam a morfologia e a sintaxe de estrofes de Camões. Esse procedimento didático não merece, de maneira alguma, o rótulo que tem recebido, de "gramática do texto", porque o que efetivamente enfoca são palavras e frases soltas, fora do texto e do contexto que motivou o seu uso.

No entanto, o exame dos livros inscritos no PNLD/2002 permitiu também a constatação de um movimento, ainda incipiente, no sentido da superação daquele abismo intransponivel entre a sintaxe e o discurso de que fala BAKHTIN (1986). Em algumas coleções foi possível reconhecer, pelo menos, o empenho em promover uma reflexão lingüística sistematizada e voltada para o uso. Em primeiro lugar, há aquelas que apresentam uma tentativa de formulação de uma "gramática textual", voltada para o que literatura acadêmica tem chamado de recursos coesivos e de operadores argumentativos. Em segundo lugar, há coleções que, sem rotular o trabalho, trazem propostas que envolvem a reflexão sobre o funcionamento das formas lingüísticas na coesão do texto, inserindo-as ora nas seções de estudo estilístico dos recursos expressivos presentes nos textos propostos para leitura, ora na discussão dos processos composicionais e das formas de discurso relatado, ora nas atividades preparatórias para a produção da escrita, ora nos exercícios gramaticais. 
Duas outras pesquisas recentes nos fornecem elementos para compreender como os professores de Português estão enfrentando suas dificuldades e perplexidades no que se refere à prática de reflexão lingüística.

A primeira, de MORAES (2000), analisa as aulas de gramática de sete professoras efetivas da rede pública de ensino de Jataí/GO, todas com Licenciatura Plena em Letras, com curso de Especialização concluído ou em andamento na década de 1990 e com participação em cursos de aperfeiçoamento nos últimos cinco anos. O perfil dessas professoras nos autoriza a suposição de que seus problemas com o ensino de gramática se mostrem atenuados em função de sua boa formação e de sua atualização. No entanto, não é isso que a pesquisa de MORAES (2000) revela. Pelo contrário, as dificuldades e as soluções verificadas nesse grupo coincidem com o que mais freqüentemente se ouve nos depoimentos de professores de Língua Portuguesa em geral. Três delas, sem saber como encaminhar com autonomia sua prática de reflexão lingüística, optam por seguir propostas de livros didáticos orientadas pelo modelo gramatical tradicional, descritivista e prescritivista. As outras quatro, também envolvidas com o ensino normativo da variedade padrão e buscando realizá-lo a partir de textos lidos ou escritos pelos alunos, não conseguem chegar a uma organização sistemática e consistente da prática de análise lingüística desenvolvida em sala de aula. As duas tendências verificadas - manter a tradição formalista da gramática da palavra e da frase ou fazer um trabalho assistemático a partir de questões lingüísticas esparsas eventualmente suscitadas pelos textos lidos ou escritos em aula - apontam em direções contrárias às recomendadas pelos PCN e não correspondem ao ideal de um ensino propício ao desenvolvimento das habilidades lingüísticodiscursivas dos alunos. As constatações do estudo de MORAES (2000) são particularmente significativas: se a perplexidade diante das propostas de mudança persiste até mesmo num grupo de professores com formação atualizada, pode-se imaginar que a maioria dos profissionais, cujas possibilidades de acesso a cursos de capacitação 
são mais restritas, devem estar enfrentando dificuldades ainda maiores, tateando na busca de um fazer pedagógico renovado, ou optando pela segurança do caminho tradicional já conhecido.

A segunda pesquisa, de RAFAEL (2001), analisando a construção dos conceitos de textos e de coesão textual em salas de aula do Ensino Fundamental e Médio da rede pública de Campina Grande/ PA, apresenta dados que apontam para um outro tipo de problema. Os professores observados também tinham passado recentemente por cursos de especialização e atualização e se empenhavam na construção de um ensino produtivo e de acordo com as últimas tendências teóricas. Entretanto, as transcrições das aulas deixam ver que, embora lidando com a noção de coesão textual e procurando orientar o trabalho para a observação e análise de fenômenos lingüísticos presentes em textos lidos e escritos na escola, os professores acabam enveredando por um tratamento formalista e classificatório que, mesmo tomando como objeto recursos de coesão textual e não estruturas morfossintáticas, pouco se distancia da orientação tradicional.

Os dois estudos mencionados, que analisaram práticas de salas de aula situadas em pontos tão distantes do território nacional, por um lado, parecem confirmar o pensamento de BRONCKART (1999) quanto à impossibilidade social de se realizar plenamente, hoje, o ensino que consideramos ideal; mas, por outro lado, também nos revelam iniciativas e movimentos na direção de um ensino em que os conhecimentos gramaticais e textuais-discursivos sejam trabalhados de maneira integrada.

Assim, reconheço nas nossas circunstâncias históricas os embates, as discordâncias, as resistências, a perplexidade, a desorientação, os equívocos, mas também um movimento de convergência em torno da proposta de superação do "abismo" entre gramática e discurso, que se faz sentir no campo da discussão teórica, em documentos e projetos oficiais que procuram balizar o ensino, como os PCN e o PNLD, em livros didáticos e no empenho e na busca de professores. 
Admitindo que o nosso "viável histórico", como disse Paulo Freire, é aceitar, por enquanto, a convivência paralela do trabalho orientado para o texto com aquele centrado na abordagem formalista de frases e palavras, quero nos próximos itens apresentar minha contribuição para o necessário trabalho coletivo de construção de um ensino mais adequado, que possa efetivar o compromisso de integrar gramática e texto.

\section{INVERTER O CAMINHO, PARA VENCER O ABISMO}

Com vista à implementação de um ensino propício ao desenvolvimento das habilidades lingüísticas dos alunos, convém, antes de discutir alguma coisa relativa aos conteúdos gramaticais, refletir quanto à orientação didático-pedagógica do trabalho em sala de aula.

Comecemos pela concepção de aprendizado e de sua relação com o ensino, na área que nos interessa.

Pode-se dizer que alguém aprende alguma coisa quando se torna capaz de reconstruí-la e explicá-la por si mesmo, por seu próprio trabalho mental, embora esse esforço intelectual se constitua sempre na relação com o outro, com os sistemas sociais de conhecimentos, crenças e valores. O conhecimento lingüístico, como todo conhecimento, não se adquire ouvindo teorias, mas se constrói na relação ativa com o objeto de conhecimento. Na primeira infância, as crianças aprendem sua língua, o que inclui a construção interna de uma gramática dessa língua, interagindo com textos falados por adultos e outras crianças à sua volta.

Se é assim que se aprende, a melhor maneira de ensinar, então, é criar situações em que o aluno tenha oportunidade de interagir com o objeto que se quer que ele conheça. Por isso acredito que, antes da conceituação e da análise gramatical, os recursos lingüísticos cujo emprego e compreensão se quer ensinar devem ser motivo de utilização intencional, observação deliberada, reflexão pessoal e interessada, descoberta por parte dos alunos. Entendo que as atividades de ensino-aprendizagem devem permitir ao aluno, primeiro, conviver 
com os recursos lingüísticos, atentando deliberadamente para seu uso e seus efeitos de sentidos nos textos que lê, experimentando-os nos textos que escreve; depois, explicitar de maneira organizada os conhecimentos que produziu, as regularidades que inferiu; e, ao final, ver suas vivências e descobertas contrapostas a alguma teoria já estabelecida.

O que estou propondo, portanto, é o abandono da metodologia que leva a expor um conceito teórico ou uma regra, ilustrar com alguns exemplos, propor exercícios de fixação e avaliar numa prova sua memorização. Minha proposta é a inversão desse caminho tradicional - teoria-exemplo-exercício -, de modo que o trabalho comece da prática para chegar à teoria, vá do concreto para o abstrato, parta do que é conhecido pelo aluno para depois the apresentar desafio do desconhecido. Esse caminho, cuja base epistemológica é a teoria sócio-interacionista de Vygotsky, parece mais de acordo com os procedimentos intuitivos de busca de compreensão do mundo e, por isso, com maiores chances de se revelar eficiente, produtivo e prazeroso na escola.

Há, no entanto, um perigo a ser evitado. O rumo do processo de ensino não pode ficar à mercê das eventuais características lingüísticas dos textos com que se trabalha. Não se pode, por exemplo, a partir de um determinado texto, propor questões sobre o uso da crase, e, a seguir, também em função do texto estudado, falar sobre o imperfeito do subjuntivo, e, logo depois, com outro texto, analisar os recursos anafóricos de coesão textual. Desse modo, não haveria sistematicidade, organicidade no processo; o ensinoaprendizagem ficaria à deriva, e os alunos não saberiam o que estariam aprendendo nem os professores saberiam o que estariam ensinando. A única maneira de evitar esse problema é definir previamente que orientação se deseja dar ao curso, prevendo o trabalho articulado e progressivo com determinados conteúdos e habilidades e selecionando, criteriosamente, os textos que servirão a esse projeto pedagógico. Entendo, pois, que o ensino será mais eficiente se se fizer de maneira planejada, consciente, sistemática, 
com os professores definindo previamente o que, por que, para que querem ensinar e, a partir daí, criando atividades e estabelecendo estratégias didáticas adequadas aos objetivos pretendidos.

Outra ressalva que considero necessário explicitar diz respeito à abordagem dada aos conhecimentos lingüísticos na sala de aula. De nada adiantará substituir os conteúdos da gramática tradicional por outros mais atuais e manter o mesmo tratamento formalista e classificatório, que só propõe aos alunos a identificação e a categorização dos recursos expressivos, sem considerar o seu uso. Por exemplo, mostrar um quadro dos recursos coesivos e pedir aos alunos que eles os localizem em textos e classifiquem, ou que com eles preencham lacunas em exercícios, é adotar, com um conteúdo "moderno", uma perspectiva idêntica à do ensino gramatical tradicional, que provavelmente não trará qualquer contribuição aos alunos para o desenvolvimento da habilidade de produzir textos adequados.

Por outro lado, mesmo lidando com conteúdos tradicionais, pode-se fazer mais pela capacidade de observação, análise e reflexão dos alunos e pelo desenvolvimento de sua sensibilidade lingüística, adotando-se procedimentos que lhes proporcionem atividade intelectual rica e até prazerosa. BRONCKART (1999), quando se refere ao eixo gramatical do ensino, propõe que se possibilite ao aluno observar e analisar conjuntos de frases previamente selecionados para daí inferir e formular conceitos e regras do sistema da língua, referentes, por exemplo à constituição de sintagmas e frases, à conjugação verbal. Essa proposta aponta na mesma direção do tratamento considerado adequado pelos PCNs e pelos critérios de avaliação do PNLD para os conhecimentos lingüísticos no nível da frase e da palavra.

Versando sobre os mesmos objetos do ensino gramatical tradicional, mas inovando quanto à direção do fazer pedagógico, que começa por criar oportunidades inteligentes de observação e análise de fatos lingüísticos, através das quais os próprios estudantes vão inferir as regularidades do sistema e formular uma descrição teórica adequada, pode-se chegar aos conceitos e regras consagrados pela 
gramática tradicional, que é o modelo teórico que o professor conhece e com o qual sabe trabalhar, porém com a grande vantagem de proporcionar aos alunos o prazer do exercício da inteligência e da descoberta e de contribuir mais eficazmente para seu desenvolvimento lingüístico e cognitivo.

Dois exemplos para dar idéia de como se pode fazer isso. Para se ensinar acentuação gráfica, conhecimento que lida com a representação convencional de determinados traços fonológicos das palavras, pode-se propor aos alunos que observem, numa página qualquer de texto escrito, quantas palavras têm acento e quantas não têm; quais são os tipos de acento que aparecem e em que "partes" da palavra eles são colocados. A classificação e quantificação dessas categorias vai tornar fácil descobrir, em vez de decorar sem entender, as regras de acentuação gráfica do português contemporâneo. ${ }^{3}$ Do mesmo modo, a observação orientada e o levantamento dos tipos de palavras que aparecem em determinado texto escrito podem levar à descoberta das classes de palavras "básicas" do português - verbos, substantivos, adjetivos, conectivos, algumas subclasses de pronomes e advérbios - e à compreensão de suas características flexionais, de seu funcionamento sintático e de seus traços semânticos comuns, bem como à percepção da complexidade do sistema, das dificuldades de se construir uma categorização coerente e dos problemas da classificação tradicional.

Resumindo, entendo que a possibilidade de se chegar a um ensino proveitoso da gramática que "acontece" no texto passa pela inversão dos procedimentos didático-metodológicos assumidos, pela adoção de um caminho que proporcione aos alunos oportunidades de observar, refletir, analisar e descobrir.

\section{A GRAMÁTICA NO TEXTO}

O processo "espontâneo", "intuitivo", de construção do conhecimento lingüístico-discursivo se desenvolve basicamente pela participação nas práticas de linguagem corriqueiras do dia-a-dia. 
Nesse processo, a gramática que se constrói é a gramática que funciona nos textos que se ouve e se fala.

Pode-se postular que esses conhecimentos discursivos e gramaticais construídos independentemente do ensino sistemático dizem respeito, prioritariamente, aos gêneros falados correntes nas situações cotidianas de uso da língua, embora se possa presumir que a interação com a televisão e o rádio crie condições para o desenvolvimento de conhecimentos e habilidades relacionados, pelo menos, à compreensão de gêneros textuais de circulação pública. A tarefa da escola seria, portanto, contribuir para a ampliação da competência lingüístico-discursiva dos alunos, possibilitando-lhes produzir e interpretar, com fluência e segurança, os gêneros textuais adequados às diversas práticas sociais de linguagem, em instâncias privadas ou públicas.

Para se pensar num ensino escolar de gramática que cumpra esse papel, deve-se, primeiro, atentar para aquilo que se pode supor que os alunos já dominam e aquilo que deseja que eles aprendam. Com apoio nas numerosas pesquisas sobre a língua falada realizadas no Brasil, na América e na Europa, podem-se apontar alguns traços comuns à gramática dos textos falados em situação coloquial: a sintaxe vai se construindo, sem planejamento prévio, à medida que o texto é composto, marcada pela ocorrência de estruturas interrompidas e reformuladas e pela predominância de enunciados curtos e justapostos ou coordenados por conectores como $e$, ai (dai), mas, $q u e$. Nos casos de subordinação, os conectores mais freqüentes são quando, se, porque. Essa é a sintaxe "boa" e funcionalmente adequada à conversa espontânea, porque seu processamento, na produção e na interpretação, é rápido e pouco trabalhoso. Por outro lado, em muitos gêneros textuais de circulação pública, escritos ou falados, observa-se a presença de períodos longos, articulados predominantemente por subordinação, onde aparece um elenco mais variado de conectores e operadores lógicos e em cuja estrutura costumam estar presentes termos e orações intercalados que podem distanciar predicado e sujeito, pronome e antecedente, por exemplo. 
Esse é o uso consagrado contemporaneamente na imprensa, na ciência, em textos didáticos, nas enciclopédias, em alguns sites da Internet e em textos falados formais, como conferências, debates públicos, pronunciamentos oficiais, sermões religiosos, discursos em solenidades. As estratégias sintáticas usuais nesses gêneros podem acarretar dificuldades de processamento que requerem experiência e "maestria" dos interlocutores. É fato que tais dificuldades podem ser atenuadas, para o produtor, pela possibilidade de preparação prévia; para o leitor, pela fixidez da escrita, que permite retomar o curso da frase, se por acaso perder o fio da meada; para o ouvinte, pela leitura pausada ou pela oratória enfática com que discursos, palestras e sermões costumam ser proferidos. Mas, ainda assim, os sujeitos envolvidos nessas práticas lingüísticas terão maiores possibilidades de serem bem sucedidos se tiverem familiaridade com esses gêneros, se seus conhecimentos lingüísticos lhes permitirem trânsito fluente na complexidade da trama macro e microestrutural desses textos.

Tomando-se, então, a sintaxe como exemplo, pode-se supor que o conhecimento gramatical que os estudantes dominam com maior fluência diz respeito à produção de enunciados curtos, justapostos, articulados sobretudo por coordenação, que convêm à interlocução falada coloquial cotidiana. E pode-se assumir como objetivo para o ensino proporcionar-lhes o domínio, também, da sintaxe usual nos gêneros textuais de circulação em situações públicas e formais, escritos e falados.

Assim uma das maneiras de encaminhar o ensino de língua portuguesa para a gramática do/no texto é cuidar da sintaxe dos textos lidos, ouvidos e produzidos pelos alunos. Como? Por exemplo, incluindo entre as atividades de leitura a reflexão epilingüística sobre períodos ou seqüências de períodos que apresentem características sintáticas que se quer focalizar. Ao propor ao aluno que atente para a estruturação interna dos enunciados dos textos lidos, o importante é criar condições para que ele perceba as relações entre os termos desses enunciados, para aprender mais sobre as variadas possibilidades de articulação frasal dos recursos expressivos da língua. Nesse caso, 
utilizar ou não a nomenclatura tradicional é pouco relevante: como o objetivo não é ensinar análise sintática, não há necessidade de privilegiar termos e conceitos, que não serão matéria de prova; por outro lado, esse tipo de trabalho pode ser uma boa oportunidade para facultar aos alunos a familiaridade com uma terminologia consagrada nos estudos da linguagem e que faz parte de nossa herança cultural (necessária até para resolver palavras-cruzadas...).

Ainda quanto à sintaxe, outra possibilidade é propor exercícios de reformulação de períodos ou seqüências de períodos encontrados em textos lidos, em textos orais transcritos, em textos escritos pelos próprios alunos, atentando-se para os modos de sinalizar ao interlocutor as relações de coesão entre os enunciados e para as diferentes possibilidades de efeitos de sentidos ensejadas pelas alterações que se fizerem.

A título de ilustração, apresento uma pequena série de exercícios que elaborei para discutir com professores do Ensino Médio num curso de capacitação ${ }^{4}$. Os exercícios versam sobre uma passagem da Proposta Curricular, também discutida durante o curso, cuja sintaxe tinha gerado dificuldade de compreensão entre os professores. O objetivo foi montar um exemplo de unidade de ensino que concretizasse as sugestões da própria Proposta, demonstrando uma possibilidade de aliar a reflexão gramatical à leitura e à produção de textos. A partir dessa exemplificação, os professorescursistas deveriam elaborar módulos de ensino destinados a seus alunos, valendo-se de textos adequados aos interesses dos estudantes.

1. Leia com atenção o parágrafo abaixo, transcrito da Proposta Curricular:

"Literatura é texto. Um tipo muito especial de texto, no qual se elabora artisticamente a manifestação verbal de vivências e reflexões; com o qual se propõe ao leitor cumplicidade e envolvimento emocional, e se lhe proporciona prazer intelectual e estético; através do qual se provoca o estranhamento ou o re-conbecimentodo cotidiano e se criam possibilidades de deslocamento, pelo bumor, pela fantasia, pelo sarcasmo. Esse tipo de texto pede, portanto, um tratamento diferenciado, que atente para sua caracterização e para a história de sua constituição sociocultural, mas pede, antes de mais 
nada, leitura, isto é, interação que se processa a partir de sua proposta estética e de sua materialidade lingüistica." (SECRETARIA DE ESTADO DA EDUCAÇÃO, 1998, p. 20-21)

2. Para explicitar sua compreensão, complemente as linhas do esquema abaixo, relativo à segunda frase deste parágrafo:

\section{no qual}

\section{com o qual}

Um tipo muito

e (com o qual)

especial de texto

\section{através do qual}

e (através do qual)

3. Responda, relacionando a primeira e a segunda frases do parágrafo:

- No texto literário, o que se elabora?

- Com o texto literário, o que se propõe? a quem?

- Com o texto literário, o que se proporciona? a quem?

- Através do texto literário, o que se provoca?

- Através do texto literário, o que se cria?

4. Pense:

- É possível identificar, na segunda frase, quem elabora, quem propõe, quem proporciona, quem provoca, quem cria?

- Que recurso lingüístico propiciou esse efeito de sentido?

- Que outros recursos, da língua falada e da língua escrita, proporcionariam efeito de sentido semelhante?

- É adequado dizer "através do qual se criam possibilidades de deslocamento"? Seria mais adequado dizer "através do qual se cria possibilidades de deslocamento"? Como você entende essas duas sentenças? Por que o verbo está no plural no texto original?

5. Reescreva as duas frases, de acordo com as propostas de reformulação que se seguem.

a) A literatura é um tipo muito especial de texto. Nesse tipo de texto, elabora-se 
Com ele,

Através dele,

b) A literatura é um tipo muito especial de texto, no qual a manifestação verbal de vivências e reflexões

6. Avalie as possibilidades de articulação das frases que você reformulou com a seqüência do parágrafo do texto original. Faça e aponte as modificações que você considerar necessárias para que o novo parágrafo não fique desconexo.

Acredito que parte dos problemas de compreensão desta passagem da Proposta Curricular estavam relacionados a dois aspectos de sua sintaxe. Em primeiro lugar, tem-se aí uma longa frase nominal que, funcionando como aposto de um termo da frase anterior, se compõe de uma seqüência de cinco orações adjetivas, por sua vez também extensas. Em segundo lugar, os verbos dessas orações adjetivas estão na chamada voz passiva sintética, tipo de construção que costuma trazer dificuldades ao falante do português contemporâneo, cuja tendência é interpretar a partícula se como sinal de indeterminação do sujeito e tomar o sujeito posposto como objeto direto, marcando, então, o verbo com a flexão de terceira pessoa do singular. O primeiro aspecto pode ocasionar a perda do fio da meada; o segundo, pode trazer dificuldades de processamento das relações entre sujeito e verbo. Os exercícios propostos tentam criar situações de análise e reflexão sobre esses dois aspectos, bem como abrir espaço para a discussão das soluções dadas pela teoria tradicional para a questão da passiva sintética. Evidentemente, o trabalho de leitura desta passagem - e de qualquer outro texto - não pode se reduzir à discussão de problemas sintáticos, mas a sintaxe é, sem dúvida, um dos fatores a ser considerado na atividade de produção de sentido, e aí reside a utilidade de exercícios desse tipo. 
Outra possibilidade de colocar a reflexão gramatical a serviço do uso textual e discursivo da língua é, analisando as frases no texto, constatar e explicar os recursos anafóricos - inclusive a elipse de termos - que as interligam entre si e com elementos do contexto. Pode-se também focalizar a ordem dos constituintes frasais e buscar compreender seu papel na progressão temática e na articulação do texto: o deslocamento de termos na oração ou no período não é questão que diz respeito apenas à estrutura sintática da frase, mas tem a ver com o jogo entre informações novas e informações dadas que se constrói no texto, com a busca de expressividade do autor, com os efeitos de sentido que pode provocar.

Um exemplo de atividade que lida com essas questões é a que transcrevo a seguir, produzida também para ser discutida no curso de capacitação de professores do Ensino Médio e que toma como objeto um parágrafo redigido por um universitário matriculado na disciplina "Redação Técnica", que a Faculdade de Letras ministra em várias unidades da UFMG.

1. Leia com atenção o parágrafo abaixo, transcrito da redação de um aluno:

"As empresas deveriam ser estimuladas pelo governo a participarem da vida escolar de seus funcionários, com incentivos fiscais, liberar funcionários mais cedo para estudar, assim sendo teriam condição de reformular também o ensino noturno, iniciando mais cedo, propiciando ao estudante/trabalhador maior participação e, conseqüentemente, melhor desempenho."

2. Parece que o autor perdeu o fio da meada. A partir de um certo ponto, parece que se esqueceu de que, ou de quem estava falando, e mudou o tópico, o tema de suas afirmações sem dar nenhum sinal dessa mudança, o que torna o parágrafo confuso e requer muito trabalho e cumplicidade do leitor.

$\rightarrow$ Para perceber o problema e saber onde interferir, tente identificar o ponto em que se rompe o fio da meada.

3. Tente também identificar qual o sujeito sintático de cada um dos predicados, na estrutura frasal construída pelo autor: 
a) quem deveria ser estimulado pelo governo a participar da vida escolar de seus funcionários?

b) quem (deveria ser estimulado pelo governo a) liberarfuncionários mais cedo?

c) quem (vai) estudar?

d) quem teria condição de reformular também o ensino noturno?

e) quem ou o que estaria iniciando mais cedo?

f) quem ou o que estaria propiciando ao estudante/trabalhador maior participação?

4. Reformule o parágrafo, buscando restabelecer a unidade temática, e procurando deixar claro para o leitor do que se fala a cada asserção, a que se refere cada oração.

$\rightarrow \quad$ Na reformulação, atente para a necessidade de indicar com clareza o sujeito sintático (e semanticamente possível e adequado), para os predicados expressos nos itens (d), (e) e (f).

Retomo agora a proposta de BRONCKART (1999, p. 88) quanto ao eixo textual-discursivo, para dedicar atenção para uma classe gramatical que tem importância fundamental na sintaxe da frase e na coesão do texto: o verbo.

A abordagem tradicional busca a caracterização formal e semântica de palavras e frases isoladas, elenca, descreve e classifica elementos, mas não contempla o emprego dessas formas e o funcionamento do sistema. No caso dos verbos, mostra as flexões de tempo, modo, número e pessoa, de formas regulares e irregulares, mesmo as que não se usam atualmente, explica a formação do subjuntivo a partir da primeira pessoa do singular do presente do indicativo, mas não diz coisa alguma sobre o emprego dessa classe de palavras, sua função na composição dos vários tipos de discurso com que se interage na vida em sociedade. Assim o aluno memoriza e "recita" conjugações, compreende a estrutura do sistema verbal, mas pode não saber como correlacionar os tempos e modos na construção da coesão e da sintaxe textual de determinados gêneros em que a articulação de formas verbais é marca constitutiva.

Pensemos na composição de tipos discursivos e seqüências textuais ${ }^{5}$ que o trabalho lingüístico da coletividade fixou em padrões 
"relativamente estáveis", como diz BAKHTIN (1992). Os tipos narrativos geralmente se constroem com os verbos no pretérito e sinalizam elementos importantes para sua significação pelo contraste entre perfeito e imperfeito, ou pelo jogo entre tempos simples e compostos (ou "conjugações perifrásticas", como prefere CÂMARA JR., 1970, p. 118 e 84-86). A partir da observação e da "conceitualização" desse padrão, pode-se não só aprender a empregá-lo quando conveniente, mas também compreender que efeitos de sentido se podem produzir fugindo-se a ele.

Outros tipos de discurso - a exposição, a argumentação, a descrição, a injunção - costumam organizar seu eixo temporal em torno do presente e sinalizar relações significativas importantes pela correlação entre os modos verbais, por recursos de modalização como os verbos modais, pelo emprego de determinadas classes léxico-semânticas de verbos (verbos de estado, de atividade, de realização, de acabamento, segundo BRONCKART, 1999, p. 279). Nos textos de tipo injuntivo, como as receitas, as instruções de uso de aparelhos e instrumentos, as regras de jogos, por exemplo, podem-se estudar os diferentes efeitos de sentido produzidos pelo emprego do modo imperativo, ou de verbos modais como dever ou ter de/que, ou do infinitivo, ou do futuro do presente, que se aliam com diferentes possibilidades de indeterminação do sujeito (o coloquial você de valor impessoal; o verbo na terceira do singular com a partícula se, mais formal; o infinitivo sem sujeito expresso).

Em síntese, entendo que focalizar em sala de aula o funcionamento textual e discursivo do sistema verbal - tempos, modos, aspectos, flexões de número e pessoa -, ao invés de lidar exclusivamente com a memorização de paradigmas regulares e formas irregulares, constitui uma das possibilidades de desenvolver práticas de análise lingüística que lidam de maneira integrada com as dimensões gramatical e textual-discursiva. 


\section{CONCLUSÃO}

Com a discussão desenvolvida e os exemplos e sugestões apresentados, espero ter cumprido meu compromisso inicial de contribuir para a construção, que há de ser coletiva, do saber didático-pedagógico relativo a o que é e como se pode ensinar a gramática do texto, a gramática que "acontece" no texto.

Para encerrar, uma palavra sobre as condições de trabalho necessárias a uma prática pedagógica consistente com os princípios aqui expostos, inspirados em reflexões recentes no campo dos estudos da linguagem e que coincidem com os assumidos pelos PCNs, pelo PNLD e por muitas propostas curriculares estaduais e municipais.

Um fazer didático como o sugerido neste artigo provavelmente requer, para a maioria dos professores, um esforço de atualização que não pode ser considerado questão pessoal, mas precisa ser institucionalmente garantido para todos os profissionais, pelo poder público e pelas escolas particulares. Novos conceitos e novas propostas estão sempre surgindo; compreender e aceitar novas idéias, a ponto de saber como lidar com elas em sala de aula, criando material didático e procedimentos metodológicos compatíveis, não é resultado que se possa esperar de um cursinho único e rápido. Por outro lado, esse tipo de trabalho só dá bons frutos quando integrado num projeto coletivo, que envolva toda a escola no empenho de mudança, com muita colaboração e troca. Por isso, é preciso haver um compromisso institucional permanente com a formação continuada dos professores e, além disso, garantia de tempo remunerado, espaço e recursos materiais para o planejamento, implementação e discussão constante do projeto pedagógico partilhado.

Proporcionar essas condições é a indispensável contrapartida do poder público e da rede de escolas particulares que, somada à disponibilidade e ao empenho dos professores, poderá tornar realidade um ensino de Português mais útil e proveitoso, mais propício a formar bons usuários da língua, isto é, cidadãos capazes de compreender o que ouvem e lêem e aptos a se expressar com pertinência e adequação, falando e escrevendo, nas diversas situações de sua vida. 
Quer me parecer, porém, que as condições para a realização desse ensino constituem mais uma conquista a ser obtida com luta, com o exercício incisivo e insistente da cidadania que tem marcado a história dos professores no Brasil.

\section{NOTAS}

${ }^{1}$ CEALE - Centro de Alfabetização, Leitura e Escritura -, da Faculdade de Educação da UFMG.

${ }^{2}$ Projeto "Avaliação de livros didáticos de Português de $5^{\mathrm{a}}$ a $8^{\mathrm{a}}$ série do Ensino Fundamental - PNLD/2002", desenvolvido no CEALE-FAE/UFMG, sob a coordenação do Prof. Antônio Augusto Gomes Batista, a partir de demanda do MEC.

${ }^{3}$ As sugestões de trabalho e os exercícios que apresento neste artigo devem muito à minha experiência de preparação de material didático "auto-instrutivo" para o Curso Não-Formal de Redação, projeto desenvolvido por um grupo de professores, monitores e estagiários do Departamento de Letras Vernáculas da FALE, de 1976 a 1983, para atender a estudantes das várias unidades da UFMG. A participação nesse grupo me rendeu muito aprendizado e ótimos amigos. A eles deixo aqui registrado o meu tributo.

${ }^{4}$ Projeto de Reformulação Curricular e de Capacitação de Professores do Ensino Médio da Rede Estadual de Minas Gerais, SEE-MG, 1997-1998.

${ }^{5}$ Para BRONCKART (1999, p. 138) os textos de qualquer gênero se compõem de segmentos nos quais se podem identificar regularidades de organização e de marcas lingüísticas, formas específicas de semiotização que traduzem a criação de mundos discursivos específicos. Essas formas regulares de organização lingüística são os tipos de discurso, que o autor classifica entre a "ordem do expor" e a "ordem do narrar", considerando ainda a relação com o ato de produção (autonomia ou implicação) e com o mundo ordinário (conjunção ou disjunção).Da conjugação desses critérios vem a distinção de quatro tipos discursivos: o discurso interativo e o discurso teórico, da ordem do expor; o relato interativo e a narração, da ordem do narrar. Os diferentes tipos de discurso se compõem de seqüências - narrativas, descritivas, injuntivas, argumentativas, expositivas e dialogais -, que BRONCKART (1999, p. 218) entende como unidades estruturais mais ou menos autônomas que se combinam na organização linear do texto. 


\section{REFERÊNCIAS BIBLIOGRÁFICAS}

BAKHTIN, Mikhail. Marxismo e filosofia da linguagem. 3. ed. São Paulo: Hucitec, 1986. (Publicação original de 1929).

. Estética da criação verbal. São Paulo: Martins Fontes, 1992. (Publicação original de 1979).

BATISTA, Antônio Augusto Gomes; COSTA VAL, M. Graça; PAULINO, Graça. Proposta curricularpara o Ensino Médio. Projeto de reformulação e de capacitação de professores do Ensino Médio da Rede Estadual de Minas Gerais. Belo Horizonte: SEE-MG, 1998.

BRONCKART, Jean-Paul. Atividade de linguagem, textos e discursos: por um interacionismo sócio-discursivo. São Paulo: EDUC, 1999.

CÂMARA JR. Joaquim Mattoso. Dicionário de filologia e gramática. 4. ed. refundida e aumentada. Rio de Janeiro: J. Ozon, 1970.

CASTILHO, Ataliba Teixeira de. Variação lingüística, norma culta e ensino da lingua materna. Subsídios à proposta curricular de língua portuguesa para o $1^{\circ}$ e $2^{\circ}$ graus. v. 1. São Paulo: Secretaria de Educação/CENP (Coordenadoria de Estudos e Normas Pedagógicas), 1987.

. Da análise da conversação para a análise gramatical. Estudos Lingüísticos - XVII Anais de Seminários do GEL. São Paulo: USP/GEL, 1989.

. Para o estudo das unidades discursivas no português falado. In:

(Org.). Português culto falado no Brasil. Campinas: Editora da UNICAMP, 1989. p. 249-280.

. Português falado e ensino da gramática. Letras de Hoje. Porto Alegre: EDIPUCRS, v.25, n 1, p.103-106, mar. 1990.

- A teoria da linguagem e a teoria gramatical. São Paulo, Departamento de Lingüística da USP, 1993 (versão preliminar, inédita)

. A lingua falada no ensino do Português. São Paulo: Contexto, 1998.

COSTA VAL, M. Graça. A interação lingüistica como objeto de ensino-aprendizagem da lingua portuguesa. Educação em Revista. Belo Horizonte: Faculdade de Educação da UFMG, n. 16, dez. 1992, p. 23-30.

FRANCHI, Carlos. Criatividade e gramática. São Paulo: Secretaria de Educação/ CENP (Coordenadoria de Estudos e Normas Pedagógicas), 1987.

. Linguagem - Atividade Constitutiva. Cadernos de Estudos Lingüisticos. Campinas: IEL/UNICAMP, n. 22, p.9-39, 1992. 
GERALDI, J. Wanderley (Org.). O texto na sala de aula: leitura \& produção. 8. ed. Cascavel: Assoeste, 1984.

. Portos de passagem. São Paulo: Martins Fontes, 1991.

. Linguagem e ensino: exercícios de militância e divulgação. Campinas: Mercado de Letras - ALB, 1996.

; CITELLI, Beatriz (Org.). Aprender e ensinar com textos de alunos. v. 1. São Paulo: Cortez, 1997.

GNERRE, Maurizzio. Linguagem, escrita e poder. São Paulo: Martins Fontes, 1985.

MINISTÉRIO DA EDUCAÇÃO - MEC. Secretaria de Educação Fundamental Parâmetros curriculares nacionais: terceiro e quarto ciclos do Ensino Fundamental - Língua Portuguesa. Brasília: MEC/SEF, 1998.

MORAES, Eliana Melo Machado. A gramática na aula de português. 2000. Dissertação (Mestrado em Educação) - Programa de Pós-Graduação em Educação da FAE/UFMG, Belo Horizonte.

NEVES, Maria Helena de Moura. A gramática funcional. São Paulo: Martins Fontes, 1997.

PERINI, Mário Alberto. Sofrendo a gramática. São Paulo: Ática, 1997.

POSSENTI, Sírio. Gramática e política. In: GERALDI, J. Wanderley (Org.). O texto na sala de aula: leitura \& produção. 8. ed. Cascavel: Assoeste, 1984.

. Discurso, estilo e subjetividade. São Paulo: Martins Fontes, 1988.

. Pelo humor na lingüística. Revista DELTA, São Paulo, v.7, n.2, p. 491520, ago. 1991 .

. Por que (não) ensinar gramática na escola. Campinas: ALB/Mercado de Letras, 1996.

. Os bumores da língua. Campinas: ALB/Mercado de Letras, 1998.

RAFAEL, Edmilson Luiz. A construção dos conceitos de texto e de coesão textual: da lingüistica à sala de aula. 2001. Tese (Doutorado) - Programa de PósGraduação em Lingüística Aplicada do IEL/UNICAMP, Campinas.

SECRETARIA DE ESTADO DA EDUCAÇÃO - MINAS GERAIS. Proposta curricular de Português para o Ensino Médio. Belo Horizonte: Secretaria de Estado da Educação, 1998. 